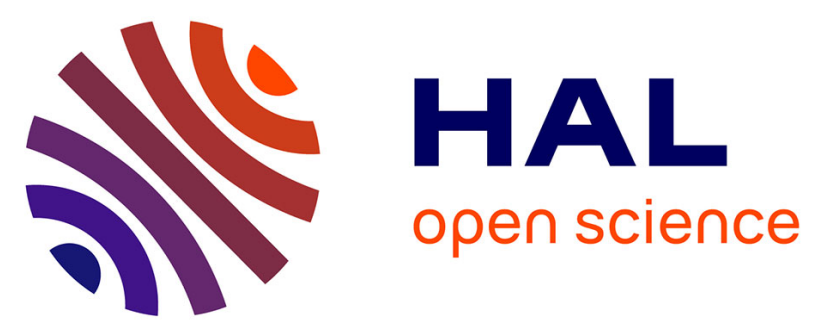

\title{
Patient Reported Outcomes and Low-level Residual HIV-RNA in Adolescents Perinatally infected with HIV-1 after Switching to One-Pill Fixed-dose Regimen
}

Raffaella Rosso, Antonio Di Biagio, F Maggiolo, Loredana Nulvesu, Annapaola Callegaro, Lucia Taramasso, Bianca Bruzzone, Claudio Viscoli

\section{To cite this version:}

Raffaella Rosso, Antonio Di Biagio, F Maggiolo, Loredana Nulvesu, Annapaola Callegaro, et al.. Patient Reported Outcomes and Low-level Residual HIV-RNA in Adolescents Perinatally infected with HIV-1 after Switching to One-Pill Fixed-dose Regimen. AIDS Care, 2011, pp.1. 10.1080/09540121.2011.596511. hal-00721643

\section{HAL Id: hal-00721643 \\ https://hal.science/hal-00721643}

Submitted on 29 Jul 2012

HAL is a multi-disciplinary open access archive for the deposit and dissemination of scientific research documents, whether they are published or not. The documents may come from teaching and research institutions in France or abroad, or from public or private research centers.
L'archive ouverte pluridisciplinaire HAL, est destinée au dépôt et à la diffusion de documents scientifiques de niveau recherche, publiés ou non, émanant des établissements d'enseignement et de recherche français ou étrangers, des laboratoires publics ou privés. 

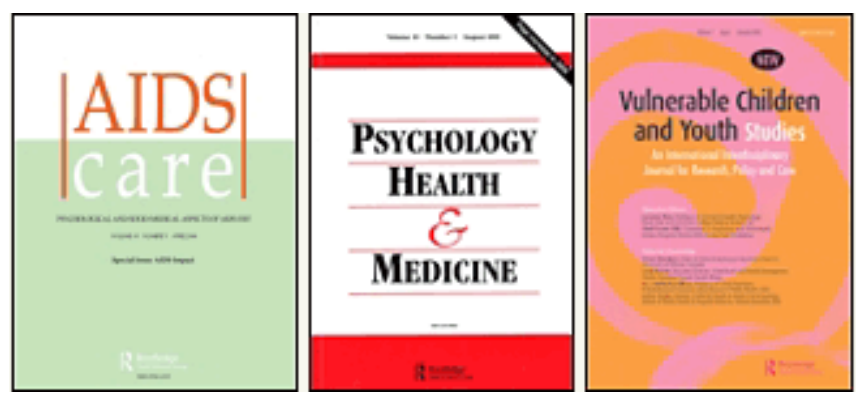

\section{Patient Reported Outcomes and Low-level Residual HIV- RNA in Adolescents Perinatally infected with HIV-1 after Switching to One-Pill Fixed-dose Regimen}

\begin{tabular}{|r|l|}
\hline Journal: & $\begin{array}{l}\text { AIDS Care - Psychology, Health \& Medicine - Vulnerable Children } \\
\text { and Youth Studies }\end{array}$ \\
\hline Manuscript ID: & AC-2010-08-0457.R1 \\
\hline Journal Selection: & AIDS Care \\
\hline Keywords: & $\begin{array}{l}\text { HIV, Adherence, Adolescents, HIV-1 Residual Viremia, once a daily } \\
\text { regimen }\end{array}$ \\
\hline \multicolumn{2}{|c}{} \\
\hline
\end{tabular}

\section{SCHOLARONE Manuscripts}




\section{Patient Reported Outcomes and Low-level Residual HIV-RNA in Adolescents Perinatally infected with HIV-1 after Switching to One-Pill Fixed-dose Regimen}

Raffaella Rosso $^{1}$, Antonio Di Biagio ${ }^{1}$, Franco Maggiolo ${ }^{2}$, Loredana Nulvesu ${ }^{1}$, Anna Paola Callegaro $^{3}$, Lucia Taramasso ${ }^{1}$, Bianca Buzzone ${ }^{4}$, Claudio Viscoli ${ }^{1}$

${ }^{1}$ Clinica Malattie Infettive, Università degli Studi di Genova, Ospedale San Martino, Genova, Italy; ${ }^{2}$ Divisione di Malattie Infettive Ospedali Riuniti, Bergamo, Italy; ${ }^{3}$ Laboratorio di microbiologia e virologia, Ospedali Riuniti, Bergamo, Italy; ${ }^{4}$ Laboratorio di Igiene, Ospedale San Martino, Genova, Italy

\section{Corresponding Author:}

Antonio Di Biagio, MD

Department of Internal Medicine and Infectious Diseases,

San Martino Hospital and University of Genoa,

Largo R. Benzi 10

16132 Genoa, Italy

Phone +390105555142

Fax +390103537680

antonio.dibiagio@hsanmartino.it 


\begin{abstract}
$\underline{\text { Abstract }}$
The choice of an antiretroviral regimen can often impact on adherence, treatment satisfaction and therefore influence on clinical outcome. These concerns are particularly true in adolescents. In this setting adherence is usually affected by multifactor events and biopsychosocial factors, which connect and change over time. We evaluated the effect of a switch to a single-pill fixed-dose regimen on patient-reported outcomes, virologic and immunologic outcomes, and safety in a cohort of adolescents with perinatal HIV-1 infection. In addition we evaluated the effect on low-level residual HIV-RNA. An open-label, nonrandomized study was performed: twelve adolescents with a confirmed viremia $<50$ copies/mL treated with lamivudine or emtricitabine, tenofovir, and efavirenz were switched to one-pill fixed-dose regimen of emtricitabine/tenofovir/efavirenz. At the end of follow-up the new regimen was associated with improvements in treatment satisfaction, HIV-symptoms, whereas adherence remained high. No immunological or virological significative changes were observed. No side effects were registered. Moreover the low-level residual HIV-RNA was $<3$ copie $/ \mathrm{mL}$ in all patients. One-pill fixed-dose regimen is an added value that favours adherence, reduces HIV-symptoms, improves patients' satisfaction, and could better control of HIV-RNA in adolescents, too.
\end{abstract}

Keywords: HIV; adherence; adolescents; once-daily antiretroviral regimen; low-level residual HIV-RNA. 


\section{Introduction}

Prospective paediatric studies have shown that the risk of virological failure increases when the proportion of missed doses increases (Van Dyke, et al., 2002; Watson \& Farley, 1999; Flynn, et al. 2004). A major obstacle to the success of therapy in children and adolescents is poor adherence. (Murphy, Wilson, Durako, Muenz \& Belzer 2001; Shah et al. 2007; Rudy, et al. 2006).

Adherence can be affected by multiple events and biopsychosocial factors, which interrelate and change over time. HIV-infected adolescents face specific adherence challenges (Ryan, et al. 2008; Belzer, Fuchs, Luftman \& Tucker, 1999). In adults several studies have identified pill burden and lifestyle issues (not carrying medication, change in schedule) as barriers to optimum adherence (Maggiolo, et al. 2002; Trotta, et al. 2003; Flandre, et al. 2002; Stone, Jordan, Tolson, Miller \& Pilon, 2004; Boyle, et al. 2008; Levi \& Drotar 1998), no data are available in children and adolescents. Moreover, in adults, a number of studies have revealed how treatment simplification strategies could enhance patients' adherence to combined antiretroviral treatment (cART) (Trotta, et al. 2003; Flandre, et al. 2002; Stone, et al. 2004; Boyle, et al. 2008). Furthermore, common HIV-related symptoms (e.g. gastro-intestinal, respiratory, neurological, constitutional, allergy and psychological discomfort) are associated with a lower adherence and their associations with worse health outcomes have been reported early in the epidemic (Harding, Molloy, Easterbrook, Frame., Higginson, 2006; Max \& Sherer 2000). A significant proportion of patients receiving cART experiences such symptoms often requiring drug discontinuation or treatment change.

Consequently, many studies have focused on describing the prevalence of HIV-related symptoms in adults and on identifying effective treatments for these symptoms (Holzemer et al. 1999). Fewer studies have examined these symptoms and their treatments in children and adolescents. 
Little is known about the preferences of adoloscents in terms of cART regimens and about factors influencing these choices.

It is also crucial to note that improved HIV-RNA assay technology has made possible the accurate detection of a low-level residual HIV-RNA, allowing the quantitation of HIV-RNA below the 50 copies/mL limit. The source and dynamics of this residual HIV-RNA are currently unknown. Viremia could arise from on-going cycles of viral replication in a sanctuary site where there is suboptimal drug penetration, from long-lived productively infected cells, or from activation of virus expression from latently infected cell reservoirs (Palmisano, et al. 2005, Bonora, et al. 2009), however, no data are actually available in children and adolescents who were vertically infected with HIV.

The objectives of the study were to verify, in adolescents perinatally infected with HIV- 1, if simplification of cART could influence: a) adherence rate, b) prevalence of HIV symptoms and c) patient's preference and how these parameter could change over time; further we analysed the effect of the simplification strategy on low-level residual HIV-RNA.

\section{Methods}

\section{Study design}

This was a 24-week, open label and descriptive study in adolescents perinatally infected with HIV-1 who had achieved virologic suppression on their current regimen containing emtricitabine (FTC) or lamivudine (3TC) + tenofovir (TDF) + efavirenz (EFV).

Patients were switched to one-pill fixed-dose regimen of FTC/TDF/EFV, then did not change their therapy in terms of active molecules or doses, but simply reduced the daily number of pills in their regimen from three or two to one. 
Due to the limits of the sample and to the uncontrolled nature of the study we limited statistical analysis to the descriptive level. Any inference would have been inappropriate due to the low power of the study. The study, therefore may only generate hypothesis for further research.

The study was approved by San Martino Hospital ethics committee. All patients or parents signed a written consent before starting study procedures.

\section{Participants}

The San Martino University Teaching and Hospital in Genoa, Italy, provides case management service to fifty-two children and adolescents born with HIV infection. Patients were selected between December 2008 and June 2009.

To be eligible, patients had to be receiving a stable cART for over six months, have an adequate weight (defined as exceeding $60 \mathrm{~kg}$ ), and a plasma HIV-1 RNA value less than 50 copies/mL using the Versant HIV-1 RNA 3.0 assay bDNA (Siemens Medical Solutions Diagnostics, Malvern, PA) at least for 6 months prior to and at screening

All twelve eligible patients were enrolled in the study. All patients related variables were collected at the moment of treatment switch (baseline) and 1,3 and 6 months after the switch. Study visits occurred at baseline, weeks 4, 12 and 24. Laboratory analyses (haematology, serum chemistries, urinalysis, and surrogate markers of HIV infection HIV-RNA and CD4 Tcell counts) and physical examinations were performed at all study visits. At the same time patients were questioned for the occurrence of adverse events.

The low-level residual HIV-RNA was quantified by ultrasensitive assay (detection limit: $<3$ copies/ml), Versant TM KPCR Molecular System (Siemens Healthcare Diagnostics).

\section{Treatment adherence}


Patient-reported adherence to treatment was assessed using a visual analogue scale (VAS). (Giordano, Guzman, Clark, Charlebois \& Bangsberg, 2004). Adherence was investigated with four separate questions considering two different recall periods: last month and last week. For each period patients were asked to report the proportion of doses taken and the proportion of doses taken with respect to the daily timing ( \pm 2 hours). In both cases a VAS scale was used to collect data.

\section{HIV symptom index}

Data were collected on 20 items self-reported questionnaire that address the presence and perceived distress linked to symptoms commonly associated with HIV or its treatment (Justice et al. 2001). The following symptom categories were addressed: gastro-intestinal symptoms (bloating, pain in the stomach, nausea and vomiting, diarrhoea or loose bowel movements); respiratory symptoms (dyspnea); neurological symptoms (peripheral neuropathy, dizziness, muscle or joint pain); psychological discomfort (change in mood, problems having sex, changes in sleep pattern, trouble remembering, changes of body appearance); constitutional symptoms (fever, headache, fatigue, loss of appetite, weight loss or wasting); and allergy symptoms (rash, skin and hair problems). Symptoms were analysed individually and collectively.

\section{Patient's preference and judgment of cART}

This aspect has been investigated by 4 items self-reported questionnaire comparing the new therapy to the previous and relating to tolerability, convenience, simplicity and potency. A value of $50 \%$ on the VAS scale indicated indifference, higher values a preferences for the one-pill fixed-dose regimen, while lower values were indicative of a preference for the previous cART. 


\section{Results}

Twelve patients were enrolled and completed the study, no patients stopped therapy due to adverse events. Of these, seven were females. The mean age was 16 years with a range from 12 to 22 years. Eleven patients were Caucasian, and one North African. According to the US Centers for Diseases Control and Prevention (CDC) revised classification system for HIV infection in children, 1 was C, 6 were A, and 5 were B. Patients had been receiving cART for a mean of 10.9 years (range 3.6 -20.1 years) and had been on their current cART for a mean of 4.1 years (range 1.2-6 years). Overall, the mean number of cART regimens the patients were exposed to was 4.6 (range 3-8). At baseline the mean CD4 T-cell count and percentage were 808.7 cells/ $\mu \mathrm{L}$ (range 419-1423) and 34.3\% (range 26-48), respectively. All patients had a HIV-RNA $<50$ copies $/ \mathrm{mL}$ and five patients $(41 \%)$ had a viral load below 3 copies $/ \mathrm{mL}$. Moreover none of the patients had significant alterations of haematological or biochemical profiles and of urine analysis.

After 6 months an increase of the median CD4 T-cell count and percentage was observed: 783 cells $/ \mu \mathrm{L}($ range $=408-1474)$, and $38.1 \%($ range $=25-50)$ respectively and all patients had a viral load below 3 copies/mL.

\section{Treatment adherence}

Adherence to treatment, as measured by the VAS, was already high at baseline being the number of doses taken in the last month and in the last week $96.6 \%$ and $99.1 \%$, respectively. Twenty-four weeks after introduction of FTC/TDF/EFV we obtained similar results $98.3 \%$ and $99.1 \%$. 


\section{HIV symptom index}

At baseline, when actively asked for, eleven adolescents reported several symptoms that could be related to the assumption of cART; seven patients $(58,3 \%)$ reported the presence of trouble remembering, whereas symptoms reported by a significant number of patients (30\%) included fatigue and muscles aches.

After 24 weeks the number of patients that reported any symptoms decreased (9 vs 11) and the number of symptoms each patient reported decreased, too (29 vs 46$)$. The most common symptoms indicated after 6 months were: trouble remembering, nausea and vomiting (25\%), and muscles aches $(16,6 \%)$.

\section{Patient's preference and judgment of cART}

The comparative evaluation of combined single tablet therapy with that based on the use of two or three tablets once-a-day is in favour of the most compact regimen both in terms of patient's preferences, tolerability, convenience and simplicity. For all considered characteristics (Figure 1), the one pill regimen was the preferred choice as early as one month after the change, and the preference for this regimen increased after 6 months.

\section{Discussion}

In our study we observed that by replacing of a 3TC or FTC, TDF, and EFV as combined tablets with one-pill fixed-dose adherence rates did not change. However, adherence rates, reported by our adolescents sample, was higher than that observed in other studies (Rudy, et al. 2010, Murphy et al. 2005) As a matter of fact, in our study, all adolescents were already a once-daily regimen (3TC/FTC + TDF and EFV) and the introduction of the one-pill fixeddose just reduced the number of pills. This change can explain the slight improvement of adherence rates we observed. 
In the present study, the switch from three or two pills to the one-pill fixed-dose was associated with sustained improvements of several symptoms commonly related to HIV infection or cART. It also crucial to note that the compact one pill was well accepted by adolescents that scored it as highly preferable in terms of simplicity, convenience, tolerability and potency. It is probable that the convenience of the one-pill fixed-dose results very charming and this may influence the patients' judgments in terms of potency. The same results were obtained in adults replacing FTC+TDF+EFV with a fixed dose combination and thus non modifying treatment in terms of type and dose of drugs (Airoldi, et al. 2010).

The efficacy of the one-pill fixed-dose was similar to the FTC or 3TC, TDF, EFV separated tablets HAART as measured by means of viral suppression and the gain of CD4 T-cells, as previously reported (Airoldi et al. 2010; Hodder et al 2010; DeJesus et al. 2009).

However it is intriguing that although only marginal the increment of adherence paralleled, in our study, the virological outcome when measured with an ultrasensitive assay for HIV-RNA. For the first time, at the best of our knowledge, in our study a simplification strategy was evaluated in adolescents, and data on low-level residual HIV-RNA were collected.

Our study had some significant limitations. The small sample and the uncontrolled design did not allow for inferential analysis An additional drawback is that our results are limited to 24 weeks of observation.

Nevertheless the strict relationship between adherence and virologic response is highlighted by our results that seem to indicate how more sensitive tests may catch even apparently nonsignificant variations of adherence.

\section{Acknowledgments}

Dr. Raffaella Rosso passed away during the development of this manuscript. She reviewed the outline and first draft in detail for clinical accuracy and intellectual content. The authors 
would like to thank the children and their parents/legal guardians for their participation in the study. 


\section{References}

Airoldi, M., Zaccarelli, M., Bisi, L., Bini, T., Antinori, A., Mussini, C., Bai, F., Orofino, G., Sighinolfi, L., Gori, A., Suter, F., Maggiolo, F. (2010). One-pill once-a-day HAART: a simplification strategy that improves adherence and quality of life of HIV-infected subjects Patient Prefer Adherence, 4:115-25

Belzer, M.E., Fuchs, D.N., Luftman, G.S., Tucker, D.J. (1999) Antiretroviral adherence issues among HIV-positive adolescents and young adults. J Adolesc Health, 25:316-319.

Bonora, S., Nicastri, E., Calcagno, A., Gonzalez de Requena, D., D'Ettorre, G., Sarmati, L., Palmisano, L., Vullo, V., Di Perri, G., Andreoni, M. (2009). Ultrasensitive assessment of residual HIV viraemia in HAART-treated patients with persistently undetectable plasma HIV-RNA: a cross-sectional evaluation. J Med Virol, 81:400-5.

Dejesus, E., Young, B., Morales-Ramirez, J.O., Sloan, L., Ward, D.J., Flaherty, J.F., Ebrahimi, R., Maa, J.F., Reilly, K., Ecker, J., McColl, D., Seekins, D., Farajallah, A., AI266073 Study Group. (2009). Simplification of antiretroviral therapy to a single tablet regimen consisting of efavirenz, emtricitabine, and tenofovir DF versus unmodified antiretroviral therapy in virologically suppressed, HIV-linfected patients. J Acquir Immune Defic Syndr, 51:163-174

Flandre, P., Peytavin, G., Meifreddy, V., Saidi, Y., Descamps, D., Delagnes, M., BrunVézinet, F., Raffi, F.; Trilège (Agence Nationale de Recherches sur le SIDA 072) Study Team. (2002) Adherence to antiretroviral therapy and outcomes in HIV infected patients enrolled in an induction/maintenance randomized trial. Antivir Ther, 7:113-121

Flynn, P.M., Rudy, B.J., Douglas, S.D., Lathey, J., Spector, S.A., Martinez, J., Silio, M., Belzer, M., Friedman, L., D'Angelo, L., McNamara, J., Hodge, J., Hughes, M.D., Lindsey, J.C., Pediatric AIDS Clinical Trial Group 381 Study Team. (2004). Virologic and immunologic outcomes after 24 weeks in HIV type 1-infected adolescents receiving highly active antiretroviral therapy. J Infect Dis, 190:271-279 
Giordano, T.P., Guzman, D., Clark, R., Charlebois, E.D., Bangsberg, D.R. (2004) Measuring adherence to antiretroviral therapy in a diverse population using a visual analogue scale HIV Clin Trials;5:74-79

Harding, R., Molloy, T., Easterbrook, P., Frame, K., Higginson, I.J. (2006) Is antiretroviral therapy associated with symptom prevalence and burden? Int J STD \& AIDS, 17:400-405

Holzemer, W.L., Corless, I.B., Nokes, K.M., Turner, J.G., Brown, M.A., Powell-Cope, G.M., Inouye, J., Henry, S.B, Nicholas, P.K., Portillo, C.J. (1999) Predictors of self-reported adherence in persons living with HIV disease. AIDS Patient Care STD, 13: 185-197

Hodder, S.L., Mounzer, K., Dejesus E., Ebrahimi, R., Grimm, K., Esker, S., Ecker, J., Farajallah A., Flaherty, J.F., AI266073 Study Group. (2010). Patient-reported outcomes in virologically suppressed, HIV-1-Infected subjects after switching to a simplified, singletablet regimen of efavirenz, emtricitabine, and tenofovir DF. AIDS Patient Care STDS, 24:87-96

Justice, A.C., Holmes, W., Gifford, A.L., Rabeneck, L., Zackin, R., Sinclair, G., Weissman, S., Neidig, J., Marcus, C., Chesney, M., Cohn, S.E., Wu, A.W., Adult AIDS Clinical Trials Unit Outcomes Committee. (2001). Development and validation of a selfcompleted HIV symptom index. J Clin Epidemiol, 54 Suppl 1:S77-90.

Lee, G.M., Gortmaker, S.L., McIntosh, K., Hughes, M.D., Oleske, J.M., Pediatric AIDS Clinical Trials Group Protocol 219C Team. (2006). Quality of life for children and adolescents: impact of HIV infection and antiretroviral treatment. Pediatrics, 117:273-83

Lee, S., Johnson, G.M., Wiznia, A., Mohan, K., Stanley, K., Morse, E.V., Krogstad, P.A., Boyle, B., Jayaweera, D., Witt, M.D., Grimm, K., Maa, J.F., Seekins, D.W. (2008). Randomization to once-daily stavudine extended release/lamivudine/efavirenz versus more frequent regimen improves adherence while maintaining viral suppression. HIV Clin Trials, 9:164-176 
Levi, R., Drotar, D. (1998). Critical issues and needs in health-related quality of life assessment of children and adolescents with chronic health conditions. In: Measuring Health-Related Quality of Life in Children and Adolescents: Implications for Research and Practice. In: Drotar D, editor. Measuring Health-related Quality of Life in Children and Adolescents. New Jersey: Lawrence Erlbaum Associates

Maggiolo, F., Ripamonti, D., Arici, C., Gregis, G., Quinzan, G., Camacho, G.A., Ravasio, L., Suter, F. (2002). Simpler regimens may enhance adherence to antiretrovirals in HIV infected patients. HIV Clin Trials, 5:371-378.

Max B, Sherer R. (2000) Management of the adverse effects of antiretroviral therapy and medication adherence. Clin Infect Dis, 30 : S96-116

Murphy, D.A., Wilson, C.M., Durako, S.J., Muenz, L.R., Belzer, M. Adolescent Medicine HIV/AIDS Research Network. (2001). Antiretroviral medication adherence among the REACH HIV-infected adolescent cohort in the USA. AIDS Care, 13:27-40.

Murphy, D.A., Belzer, M., Durako S.J., Sarr M., Wilson C.M., Muenz L.R.; Adolescent Medicine HIV/AIDS Research Network. (2005) Longitudinal antiretroviral adherence among adolescents infected with human immunodeficiency virus. Arch Pediatr Adolesc Med, 159:764-760

Nachman, S., Pediatric AIDS Clinical Trials Group Adherence Subcommittee (2002). Reported adherence as a determinant of response to highly active antiretroviral therapy in children who have human immunodeficiency virus infection. Pediatrics, 109:61

Palmisano, L., Giuliano, M., Nicastri, E., Pirillo, M.F., Andreotti, M., Galluzzo, C.M., Bucciardini, R., Fragola, V., Andreoni, M., Vella, S. (2005). Residual viraemia in subjects with chronic HIV infection and viral load $<50$ copies/mL: the impact of highly active antiretroviral therapy. AIDS, 19:1843-7. 
Paterson, D.L., Swindells, S., Mohr, J., Brester, M., Vergis, E.N., Squier, C., Wagener, M.M., Singh, N. (2000). Adherence to protease inhibitor therapy and outcomes in patients with HIV infection. Ann Intern Med, 133:21-30

Ryan, M., Griffin, S., Chitah, B., Walker, A.S., Mulenga, V., Kalolo, D., Hawkins, N., Merry, C., Barry, M.G., Chintu, C., Sculpher, M.J., Gibb D.M. (2008). The cost-effectiveness of cotrimoxazole prophylaxis in HIV-infected children in Zambia. AIDS, 22:749-757

Rudy, B.J., Lindsey, J.C., Flynn, P.M., Bosch, R.J., Wilson, C.M., Hughes, M.E., Douglas, S.D., Pediatric Aids Clinical Trials Group 381 Study Team. (2006). Immune reconstitution and predictors of virologic failure in adolescents infected through risk behaviours and initiating HAART: week 60 results from the PACTG 381 cohort. AIDS Res Hum Retroviruses, 22:213-21

Rudy, B.J., Murphy, D.A., Harris, D.R., Muenz, L., Ellen, J., Adolescent Trials Network for HIV/AIDS Interventions. (2010). Prevalence and interactions of patient-related risks for non adherence to antiretroviral therapy among perinatally infected youth in the United States. AIDS Patient Care STDs, 24:97-104

Van Dyke, R.B., Lee, S., Johnson, G.M., Wiznia, A., Mohan, K., Stanley, K., Morse, E.V., Krogstad, P.A., Nachman, S., Pediatric AIDS Clinical Trials Group Adherence Subcommittee Pediatric AIDS Clinical Trials Group 377 Study Team (2002). Reported adherence as a determinant of response to highly active antiretroviral therapy in children who have human immunodeficiency virus infection. Pediatrics, 109:e61.

Stone, V.E., Jordan, J., Tolson, J., Miller, R., Pilon, T. (2004). Perspectives on adherence and simplicity of HIV-infected patients on antiretroviral therapy. Self-report of the relative importance of multiple attributes of Highly Active Antiretroviral Therapy (HAART) regimens in predicting adherence. J Acquir Immune Defic Syndr, 36:808-816

Trotta, M.P., Ammassari, A., Cozzi-Lepri, A., Zaccarelli, M., Castelli, F., Narciso, P., Melzi, S., De Luca, A., Monforte, A.D., Antinori, A., Adherence Italian Cohort Naive 
Antiretrovirals (AdICONA) Study Group; Adherence Spallanzani (AdeSpall) Study Group. (2003). Adherence to highly active antiretroviral therapy is better in patients receiving non-nucleoside reverse transcriptase inhibitor-containing regimens than those receiving protease inhibitor-containing regimens. AIDS, 17:1099-1102

Watson, D.C., Farley, J.J. (1999). Efficacy of and adherence to highly active antiretroviral therapy in children infected with human immunodeficiency virus type 1. Pediatr Infect Dis J, 18:682-689 


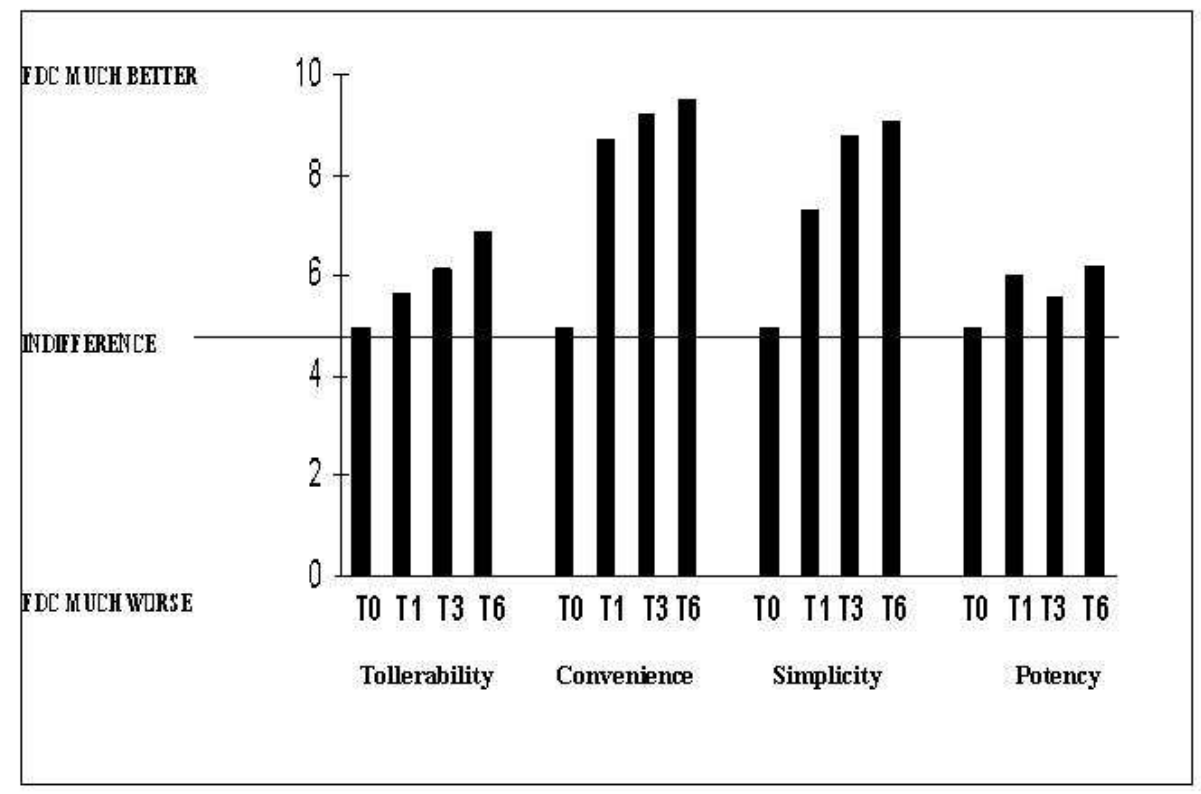

Figure 1: Patients preferences. Patients option was in favour of the fixed dose combination (FDC) compared to the single drug pills (T0)

$254 \times 190 \mathrm{~mm}(72 \times 72$ DPI $)$ 